\title{
Optimum Control Strategy Of MTG - Grid Tie With Isolated Dc Grid Using GA-PI And Bidirectional Svpwm Converter
}

\author{
Hasan Wahhab Salih", , Shaorong Wang ${ }^{1}$, Bashar Sakeen Farhan 1,3 \\ ${ }^{1}$ Huazhong University of Science and Technology, Wuhan, China \\ ${ }^{2}$ Ministry of Electricity, Al Furat-Middle General Directorate of Electricity Region, Republic of Iraq \\ ${ }^{3}$ Baghdad governorate - Baghdad governorate Directorate of water, Republic of Iraq \\ hasanrabee@hust.edu.cn
}

Keywords: MTG; GA-PI; dc-dc buck converter; bidirectional DC - AC converter; SVPWM

\begin{abstract}
In the grid connection mode, many power generation companies prefer to install microturbine (MTG) as it provides high inertia to the system, requires less maintenance, high efficiency, able to burning many types of fuels as compare with another type of conventional power generation such a diesel generator. The MTG coupling with a permanent magnet synchronous generator (PMSG) and an uncontrolled rectifier, dc/dc buck converter and bidirectional DC to AC are utilized. The Conventional (MTG) speed control's system has been widely used leg-lead or PI controllers and this PI, mostly manually tuned by trial and error methods to regulate the microturbine rotor speed respected to the set point. This conception tends to the inefficient dynamic behavior to the system. In this paper, the authors proposed two contributions: first, developing the model of the high-speed micro-turbine to obtain the optimum controller parameter of MT governor by an optimizing PI speed controller of MTG using GA-PI Second, it is designing the bidirectional AC to Dc converter based SVPWM, the reason of an employed bidirectional converter here because the author had proposed the dc micro grid that is attached to dc link of rectified MTG power, so, during normal condition, the MTG can provide the dc micro grid and provided the AC main grid with it full power, while when the dc micro grid demand has become bigger than MTG full load, the bidirectional draw power from grid and supplied the dc load demand as well as this converter responsible to stabilize the dc link and extract the full power from MTG. Furthermore, the author proposed extra AC link from the grid to running the MTG during startup mode (motor mode of PMSG) so not need to bidirectional power electronic interface in machine side converter. By used MATLAB/ Simulink as implementation software.
\end{abstract}

\section{Introduction}

Microturbine generation system (MTG) widely used over whole the world as grid / isolated mode connection because it has high efficiency, faster response, not needs to high-cost maintenance, and higher reliability as compare with other non-renewable energy power generation. The microturbine is able to burning many types of fuels at different levels of pressure, including, waste gas, natural gas, landfill gas[1]. The rated power of micro-turbine is around $10 \mathrm{~kW}$ to $1 \mathrm{MW}$ while the conventional gas turbine from $1 \mathrm{MW}$ to more than 100 MW. Generally, in the industrial side, the MTG can classify into two types. First, is the high-speed single shaft MTG, where turbine and generator are coupling on the same shaft, and it has been presented in[2]. Second, is the splitshaft MTG system, where a generator took torque from the gearbox, and this gearbox have already connected with the main shaft of MT[3]. Detail's information and operation theory of the micro gas turbine has been presented in [4].The emissions of MT is around eight times lower than a diesel engine, and produce less than $50 \%$ of the NOx emissions [5]. The modeling of MT with a permanent magnet synchronous generator (PMSG), induction generator (IG) or synchronous generator (SG) based $\mathrm{AC}$ to $\mathrm{DC}$ rectifier then $\mathrm{DC}$ to $\mathrm{AC}$ by an inverter for grid/isolated grid with conventional control has been reported in [6-10].In [10] and for standalone MTG power plants, the authors made a comparison between two types of the controller the first one is based on artificial neural network (ANN) and the another one is the conventional PI controller. There is three control loop in MTG: first is acceleration control. Secondly, speed governor control and the third is temperature control. The speed governor considered as main control loop and its need to robust control to regulate the turbine speed to the set point. Many studies deal with MT use's lead-lag or PID controller as speed regulator and this reported in [11]. The problem of used PID controller which is tuned by the trial and error method reduces the system reliability, has a poor response time and high overshooting that will be active directly on the machine.

Fig. 1 shown the overview of the proposed modeling power system.

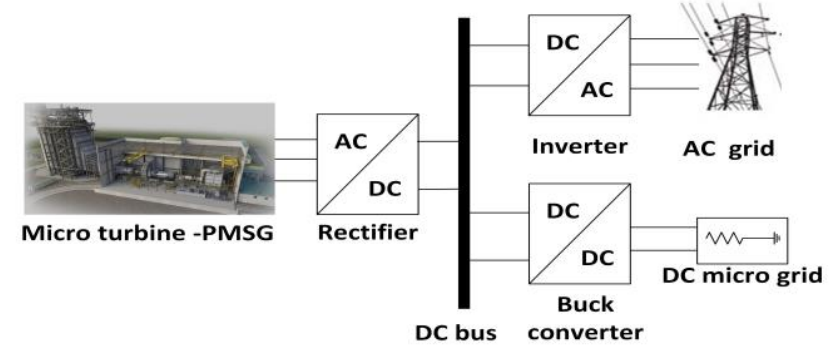

Fig 1. MTG based grid tie with de microgrid 
Now a day, an artificial intelligence based algorithm has been used in many applications to find the optimal solutions. It is a meta-heuristic computational searching method, which optimizes desired parameters by continuously iterating the parameter until the solution with given measure of quality is achieved. The author used the genetic algorithm as a search technique to obtain an optimum value of $(\mathrm{Kp}, \mathrm{Ki})$ of $\mathrm{PI}$ controller.

In additional, in this paper, the author propped variable load DC microgrid that is connected to same MTG dc link and used bi-directional converter based upon SVPWM technique to get high power flow between dc link (dc microgrid) and $\mathrm{AC}$ main grid. However, the employment of bi-directional DC/AC converter is to stabilize, regulate the $\mathrm{dc}$ voltage and extracted the maximum power from MTG.

The paper is organized as follows. Section II shown the model details. Section III shown the control strategy of the model. Section IV showed the proposed GA tuned PI control of MTG rotor. Section V showed the simulation results. Section VI shown the conclusions.

\section{Model Details}

\subsection{Micro turbine configuration}

The components of MT system are the turbine, burners, compressor, generator and electronics with power devices. Actually, the MT is a heavy duty gas turbine, the principle of operation is based upon the Brayton cycle[5]. The basic conception of MT, the inlet air is compressed in a radial compressor then mixed with fuel in the combustor and finally burned, in the last step, the hot combustion gas is then entered in the turbine, the conversion of heat to mechanical energy produces rotating of the main shaft to drive the generator and compressor because it the MTG has been coupled with compressor to the same shaft.

By depending on reference [7] the authors have been used the same description of the mathematical model. It's including speed governor control, fuel valve control, temperature control and exhaust calculation.

Generally, MTG has many control loops includes:

- Start-up

- Acceleration

- Speed

- Temperature

- Shutdown and

- Manual Control

Fig.2 shows the main control function of microturbine. The output of this controller is processing to generate fuel stroke reference, and it's considered as a signal to fuel flow. The master controller is to select the lowest of the three controls loops and to establish the fuel input to the turbine at rating required by a system then just only ONE control loop will be in online at any time.

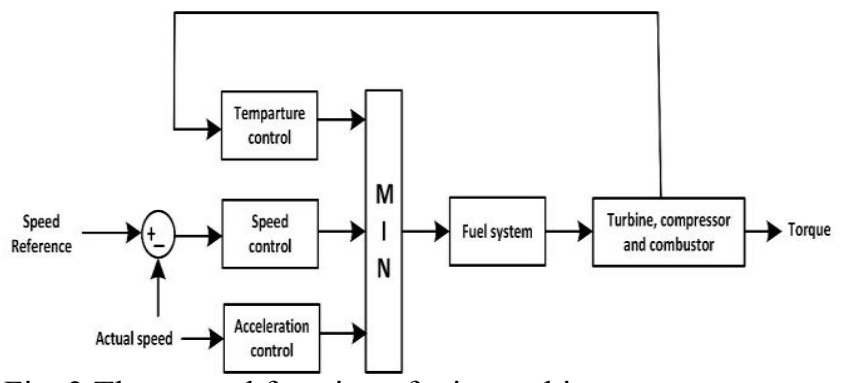

Fig. 2 The control function of microturbine

The detailed model of MTG subsystem presented in the following parts:

a. Acceleration control

This controller is used primarily during startup of MTG to limit the rate of MT acceleration prior to reaching operating speed, then the output of it tends to the minimum gate as shown in Figure 3.

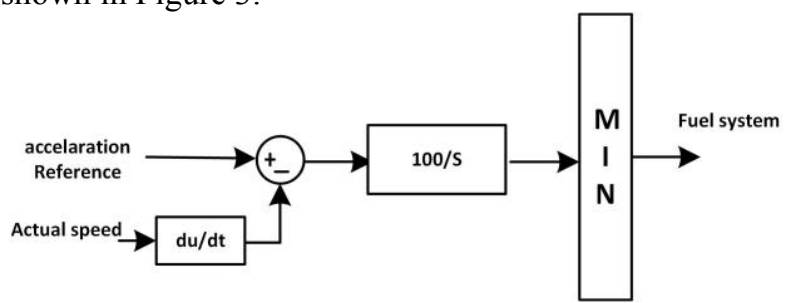

Fig.3 Acceleration control

b. Speed control

Generally, the speed control is acting under part load conditions. It is used to regulate the rotor speed to set point value by reducing the error. Many studies have used compensators such as lead-lag or a PID controller[11]. In this chapter, the trial and error method used to tuning the PI controller parameters that it utilized to regulate speed governor of MT as shown in figure 4.

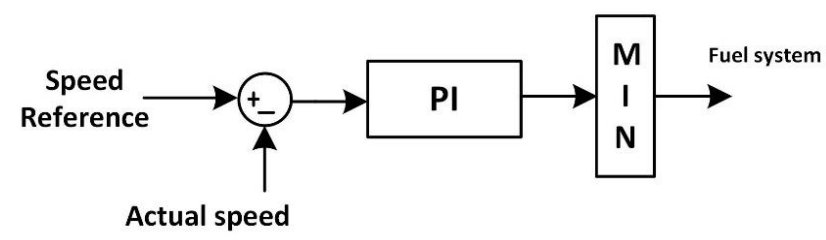

Fig.4 Speed control of MTG

c. Fuel system

MTG able to burn many kinds of fuel such as natural gas, liquid fuel, and heavy fuel. The fuel system including two main valves. First, is stopped off valve, and second is a control valve with its actuator[12].

The following transfers function can be express for the valve positioner and actuator as:

$$
\begin{aligned}
& E_{1}=\frac{K_{v}}{T_{v}+c} * \mathrm{~F}_{d} \\
& W_{f}=\frac{K_{f}}{T_{f} s+c} * E_{1}
\end{aligned}
$$

Where: Fd and E1 are command signal for fuel flow and an input signal for fuel system actuator respectively. Kv and 
$\mathrm{Kf}$ are the valve position and actuator gains respectively. Tf and $\mathrm{TV}$ are the fuel system actuator and valve positioner time constants respectively, and $\mathrm{Wf}$ is fuel demand.

Fig 5. shows the block diagram of the minimum gate output represented at Vce where it is the amount of fuel required by $\mathrm{MTG}$.

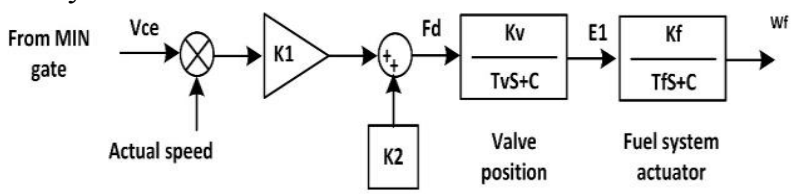

Fig. 5 Fuel system block diagram.

Where $\mathrm{K} 2$ is the minimum amount of fuel flow at no load and $\mathrm{K} 1$ is just gain.

\section{d. Turbine \& compressor}

The Turbine is considered as main part of the microturbine. Generally, the gas turbine is non-dynamic and linear while the compressor is a dynamic device, and it's consisted of some stages of blades arranged as a fix and moved stages. Most of the pressurized air used in the combustion chamber and other used for cooling the turbine blades and pneumatic control for some valves inside microturbine system. If the input of compressor changed, the output of it can't change directly that is a reason to used time lag TCD. The combustion reaction associated with time delays TCR. Figure 6 shown the block diagram of turbine compressor system.

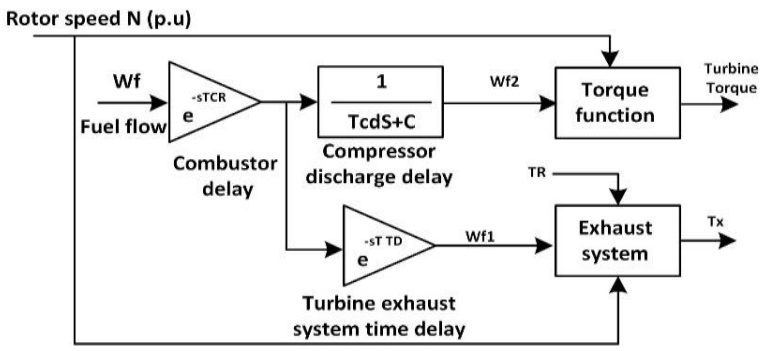

Fig. 6 Block diagram of Turbine-compressor

The torque and exhaust temperature equation of microturbine can be given by the following equations:

$$
\begin{aligned}
& \text { Torque }=K_{H H V}\left(\mathrm{~W}_{f 2}-0.23\right)+0.5(1-N) \\
& T x=T_{R}-700\left(1-W_{f 1}\right)+550(1-N)
\end{aligned}
$$

Where: Torque in N.m and exhaust temperature in $F^{\circ} ; K_{H H V}$ is a coefficient and it's depending on the enthalpy value of the gas stream in the combustion chamber and $T_{r}$ : is temperature reference.

\section{e. Temperature control}

When the load demand of the MTG is increased, the output power increased too. The increasing in output power makes rising in the exhaust temperature and when the exhaust temperature exceeds the rated, the temperature control loop passes via a minimum gate to generate the fuel control signals as shown in Figure 2.1. The ambient temperature effect of the temperature limit and in the case of increasing the ambient temperature, the exhaust temperature will tend to increase and the temperature control loop will be acting to reduce the amount of fuel consumption of the microturbine. Normally the exhaust temperature measured by used thermocouples. Figure 2.7 shows the temperature control loop of microturbine and it's represented as a mathematical model and transfer function.

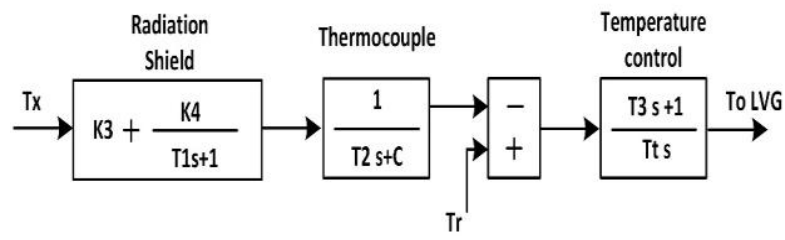

Fig.7 Temperature control

\subsection{Permanent Magnet Synchronous Generator (PMSG)}

The MT is coupled with high-speed PMSG (10,000 to $120,000 \mathrm{rpm})$ to generate the power with high frequency. PMSG is a generator doesn't feed by excitation system and coil while it's fed by a permanent magnet. The PMSG has some advantages such as higher power density and efficiency, does not need to dc or coil and excitation system so no filed copper loss, lower rotor inertia. The drawbacks are no control of field flux and possible demagnetization so the voltage of the machine cannot be easily regulated and it has higher cost [13]. To design proper permanent magnet synchronous generator should select proper materials. High-performance PMSG can produce a high level of the magnetic field with low mass. The PMSG construction consists of several parts such like a permanent magnet, rotor's steel sheet, copper for windings and stator laminations. Suitable materials are chosen to provide sufficient electromagnetic performance and average cost. According to the conception of dq0 axis for PMSG and to make a balanced system [14], the Vd and Vq equations can be written as:

$$
\begin{aligned}
& V_{d}=R_{s} i_{d}+L_{d} \frac{d i_{d}}{d t}-p \omega_{r} L_{q} i_{q} \\
& V_{q}=R_{s} i_{q}+L_{d} \frac{d i_{q}}{d t}+p \omega_{r} L_{d} i_{d}+p \omega_{r} \phi_{m}
\end{aligned}
$$

Where: Rs is stator resistance of PMSG, $\phi_{m}$ is flux linkage of PMSG, DQ inductances can represent as Ld and Lq respectively, the DQ axis voltage represent as $\mathrm{Vd}$ and $\mathrm{Vq}$ respectively. The mathematical equation of electrodynamic torque can represent as:

$$
T_{e}=\frac{1}{2} p\left[\phi_{m} i_{q}+\left(L_{d}-L_{q}\right) i_{q} i_{d}\right]
$$

The motor dynamics mathematical expression can be given as

$$
\begin{aligned}
& \frac{d}{d t} \omega_{r}=\frac{1}{J}\left(T_{e}-F \omega_{r}-T_{M}\right) \\
& \frac{d}{d t} \theta_{r}=\omega_{r}
\end{aligned}
$$

The electromagnetic torque is $\mathrm{Te}$, the mechanical torque is $\mathrm{Tm}$, the number of pole pairs is $\mathrm{P}$, the rotor speed is wr, the 
viscous friction of rotor is $\mathrm{F}$, the moment of inertia for PMSG is $\mathrm{J}$, and the angular position is $\theta \mathrm{r}$.

Through the Park transform and from variables $\mathrm{ABC}$ can find the $\mathrm{d}$, $\mathrm{q}$ variables, and vice versa to find $\mathrm{ABC}$ through the inverse of the Park transform[13].

$$
\left[\begin{array}{l}
v_{q} \\
v_{d} \\
v_{0}
\end{array}\right]=\frac{2}{3}\left[\begin{array}{ccc}
\cos \theta_{r} & \cos \left(\theta_{r}-120\right) & \cos \left(\theta_{r}+120\right) \\
\sin \theta_{r} & \sin \left(\theta_{r}-120\right) & \sin \left(\theta_{r}+120\right) \\
1 / 2 & 1 / 2 & 1 / 2
\end{array}\right]\left[\begin{array}{c}
v_{a} \\
v_{b} \\
v_{c}
\end{array}\right]
$$

\section{Model Control Strategy}

\subsection{Bidirectional AC-DC converter}

Initially, the MTG draw power from the grid by used AC link attached with power transformer to startup it via run the PMSG as a motor (motor mode) through controlled interlocking circuit breaker between AC link and the link that is connected to the uncontrolled rectifier as shown in figure 8 .

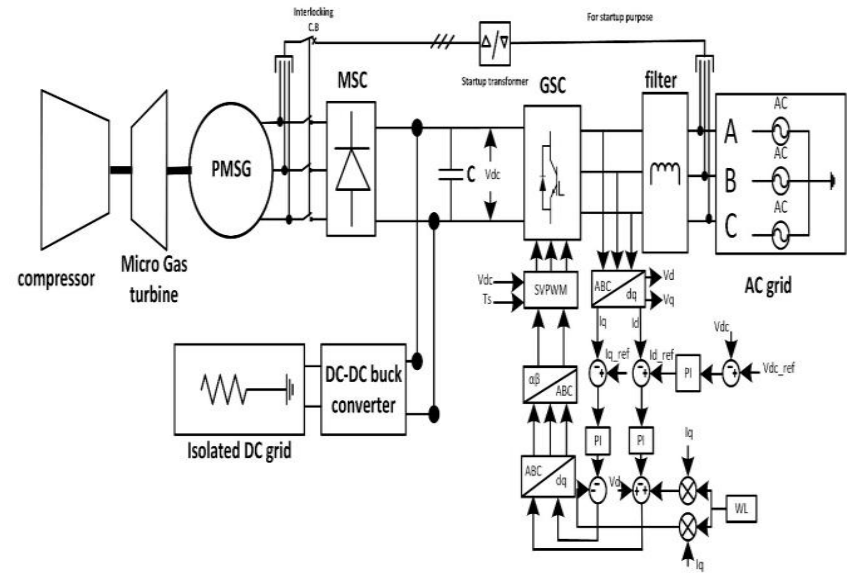

Fig. 8 configuration of MTG grid tie with dc isolated grid

During the start-up mode, the PMSG operated in motor mode and when the start-up is completed the circuit breaker changed its status and now converted the rotational of PMSG to generator mode. In proposed work, the uncontrolled rectifier is converted the high rate frequency power of MTG to Dc power, then employed bidirectional DC to AC inverter to stabilize the dc link voltage and extracted the full power from MTG. The reason of employed bidirectional AC to DC inverter in proposed work because the DC micro grid has been connected with same DC link of MTG. There are several cases can be achieved in proposal design as the following points:

- If there is no dc load, the MTG will provide its full power to $\mathrm{AC}$ grid and here the Bidirectional tasks just to regulate the DC link and converted the dc power to $\mathrm{AC}$ power that is injected into AC grid.

- If the DC load is smaller than MTG full power, the MTG provided this load and the other generated power from MTG will be injected to AC main grid by the inverter.

- If the DC load is equal to MTG full power, the MTG provided this load and the task of the inverter is just to stabilize the de link.
- If the DC load is bigger than MTG full load, the MTG provided its full power and the bidirectional inverter will draw back the required power from $\mathrm{AC}$ main grid to dc link to stabilize it and provided the DC load demand.

In another meaning, dc link comprises with a load of dc micro grid, so, the utilization of the bidirectional inverter able to draw back the power from AC grid or inject the power from MTG to the Ac main grid based upon the generation/loading conditions.

In order to achieve that, Bi-directional $\mathrm{AC}$ to $\mathrm{Dc} / \mathrm{Dc}$ to Ac based SVPWM utilized in this section, it has the ability to stabilize the Dc link voltage, extracted maximum power from MTG and allowing the power flow between de link and main Ac grid. Power flow between hybrid grids is very important to cover any demand deficiency in the DC micro grid due to all conditions. Moreover, if there are renewable energy sources in dc microgrid and in the case of abundant in this renewable energy power, the bi-directional will observe the extra energy to main Ac grid [15].

The vector control (VC) employed to decoupling the controller and get the Unity Power Factor (UPF) by set Iq as zero.

The equations of the reactive and active power can be written as follows:

$$
\begin{aligned}
& Q=\frac{3}{2}\left(v_{d} i_{q}-v_{q} i_{d}\right) \\
& P=\frac{3}{2}\left(v_{d} i_{d}+v_{q} i_{q}\right)
\end{aligned}
$$

The controller consists of an outer control loop to regulate the dc link voltage. It also consists of an inner loop to decouple the direct and quadrature components of the current to control the active and reactive power independently. From figure $.2-14$, the grid side inverter voltages is given by:

$$
\left\lfloor\begin{array}{l}
e_{a} \\
e_{b} \\
e_{c}
\end{array}\right\rfloor=R_{f}\left\lfloor\begin{array}{l}
i_{a} \\
i_{b} \\
i_{c}
\end{array}\right\rfloor+L_{f} \frac{d}{d t}\left\lfloor\begin{array}{l}
i_{a} \\
i_{b} \\
i_{c}
\end{array}\right\rfloor+\left\lfloor\begin{array}{c}
v_{a} \\
v_{b} \\
v_{c}
\end{array}\right\rfloor
$$

Where: $e_{a}, e_{b}, e_{c}=$ output voltages at inverter

$R_{f}=$ filter resistance. $i_{a}, i_{b}, i_{c}=$ line currents; $L_{f}=$ filter inductance; $v_{a}, v_{b}, v_{c}=$ grid voltage components

The equation of the grid-side converter is given by equation $(14,15)$ after converting the equation number (13) to voltage vector.

$$
\begin{aligned}
& v_{q}=e_{q}-R_{f} i_{q}-L_{f} \frac{d i_{q}}{d t}-w L_{f} i_{d} \\
& v_{d}=e_{d}-R_{f} i_{d}-L_{f} \frac{d i_{d}}{d t}+w L_{f} i_{d}
\end{aligned}
$$

Where: $\left(e_{q}, e_{d}\right),\left(v_{q}, v_{d}\right)$ inverter d,q-axis voltage components and grid voltage components in the d,qaxis. $i_{d}, i_{q}=\mathrm{dq}$ - axis current of the grid. $\mathrm{w}=$ network angular frequency.

Figure 9 shown the block diagram of a control circuit for voltage source converter based upon decoupling [16, 17]. 


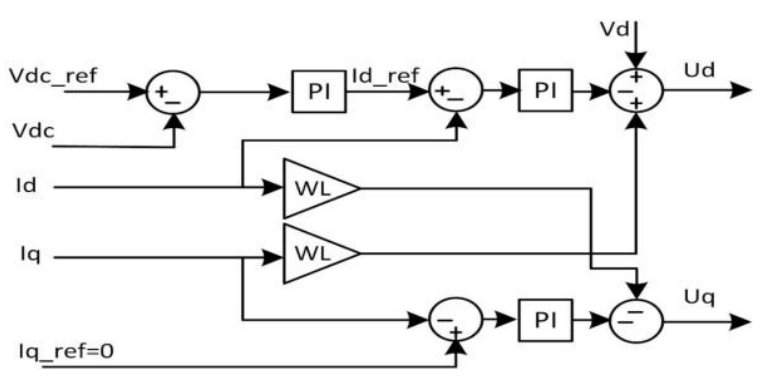

Figure 9. Block diagram of VSC control

\section{Proposed Intelligent Controller (GA-PI)}

Because the conventional methods of tuning the pi controller such as trial and error have lacked the dynamic behavior of the hybrid power system (speed governor in MTG system and bi-directional for BESS) and to overcome these problems, the authors have been used a genetic search algorithm to tuning PI parameters gains and got optimum values. Goldberg has developed the genetic algorithm according to Darwin's theory of evolution which voiced that any survival of an organism must be affected by the rule "the strongest species that survives"[18].

An adaptive searching mechanism can provide by uses GA. The solutions in a population are expressed by chromosomes; each of them is coupled with to a problem evaluation (fitness value). The chromosomes are subjected to an evolutionary progress which takes many cycles[19]. The basic process is selection, reproduction, mutation and crossover. Parent selection produces a more reproductive probability of the fittest individuals. In the case with crossover process, some new individuals cross and exchange their genetic characteristics. When the mutations procedure is coming it will make a randomly changing in the genetic material, this lead to give variety and an updating in the population. The evolution process guides the GA through more promising places in the search space. The advantages of using GA are efficient, not need to the robust mathematical representation for the problem, it is considered a global search technique, and it can be met to the optimization of any illstructured problems. Furthermore, GA is robust, can apply to many problems, then the optimal solution may be found, Figure 16 shown the flowchart of the GA.

The progress of tuning will start with given definition to the chromosome, according to the problem parameters, the chromosome is restructured by $\mathrm{N}$ values that correspond to the $\mathrm{N}$ parameter gains to be adjusted in order to get optimal values. Both gain $\mathrm{Kp} \& \mathrm{Ki}$ is real numbers, and it will characterize as an individual to be evaluated.

The choosing of objective functions is a main and important step in GA because each evaluates the fitness of the chromosome used it. There are many objective functions [20, 21] such as MSE, IAE, and ISE as the following equations: Where $\mathrm{e}(\mathrm{t})$ is the error signal.

$$
M S E=\frac{1}{t} \int_{0}^{\tau}(e(t))^{2} d t
$$

$$
\begin{aligned}
& I S E=\int_{0}^{\tau} e(t)^{2} d t \\
& I T S E=\int_{0}^{\tau} t e(t)^{2} d t
\end{aligned}
$$

The objective function is to minimize and reduce the error between the reference (desired value) and the actual output (real value), in this work the authors used integral of the squared error (ISE) as the fitness function.

In this work, the chromosome's representations are encoded the PI gains Kp, Ki into binary strings. The length of strings is taken 16 to each dimension and because the pi has two gains so it is set to $32(16+16)$. The selection process is implemented on a population of chromosomes then it leads to creating forms known as mating pool. In this paper, the authors use roulette wheel parent selection, after that, the crossover process is executed to create new chromosomes. Same as the real, the crossover will generate new individuals carrying some gene parts of parents. It is analogous to biological mutation. In each chromosome, the fitness is constituted by transforming its binary string to a real value which forms PI gains as shown in fig.9. The fitness function of the speed governor system in MTG will be given as:

$$
I S E_{\text {speed }(M T G)}=\int_{0}^{\tau}\left(w_{\text {reference }}(t)-w_{\text {actual }}(\mathrm{t})\right)^{2} d t
$$

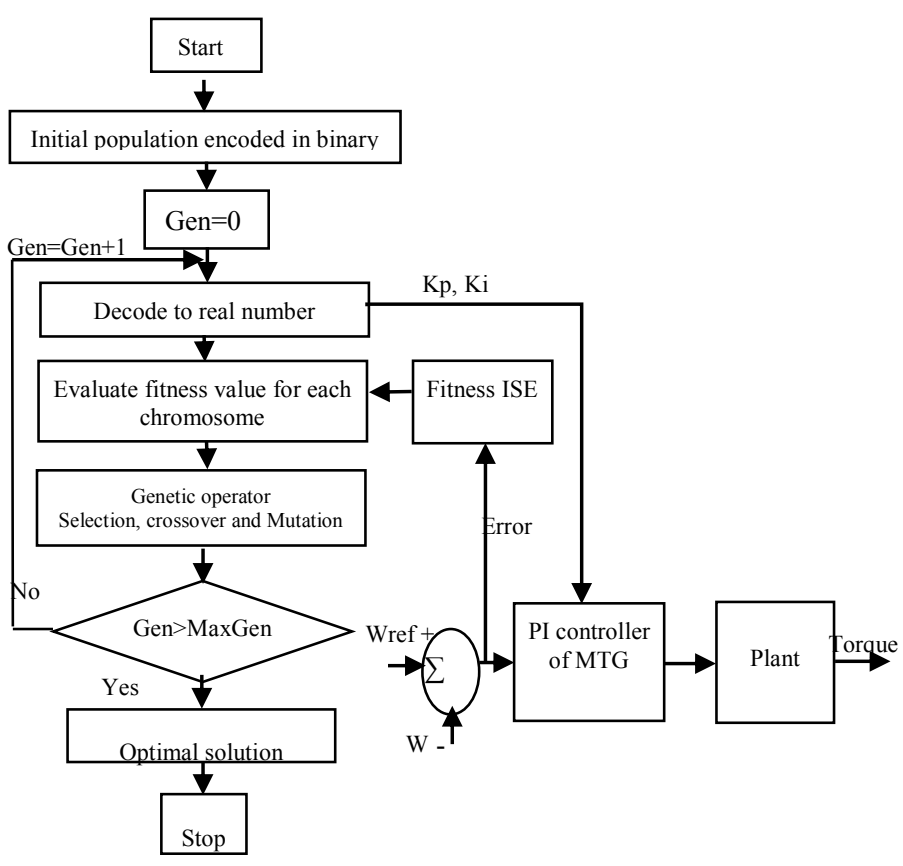

Fig.10 Flowchart of the GA-PI

\begin{tabular}{|l|l|}
\hline GA parameter & value \\
\hline Number of generation & 10 \\
Population size & 10 \\
Length of chromosome & 2 \\
Crossover probability & 0.5 \\
Mutation probability & 0.01 \\
\hline
\end{tabular}

Table.1 Genetic algorithm parameters 


\section{Results and Simulation}

Some of the scenarios have been implemented in this work as the microturbine is connected to the main grid via bidirectional Ac/Dc converter, the task of the bidirectional converter is to stabilize the dc-link voltage by injecting or suck power to/from Ac-grid, also the dc microgrid has been attached with DC link. All results have been shown in Figures (10 to 15$)$ :

a. Startup of MTG (MTG power $=0$ as startup mode):

Normally, in this case, the micro turbine started up by PMSG in motor mode and it needs some time to reach to full speed no load after that it can generate the required power (full load of MTG, 1 p.u). It's taken around more than 2.5 seconds to reached to steady state speed in the case without optimization method, while taken just 0.9 seconds in case GA-PI.

\section{b. Full speed of MTG}

During this case and after the MTG reached to full speed (1 p.u) it started to generate the full power and inject it to AC grid by used bidirectional inverter. There is no demand of dc load, the MTG will supply its power (1.p.u) to main Ac grid by Ac to Dc inverter till second 5.

c. During demand of Dc load

Between (5-7) seconds of simulation time, the dc load draws the power from dc link around ( 0.2 p.u $)$ by used dc/dc buck converter that supplied the dc load, So the MTG able to provide this load and in same time the Ac/Dc inverter taken the reminder power of MTG then injected it to main grid $(0.8$ p.u) of MTG inject to Ac grid. Between 7- 9 seconds the dc load demand increased nearest to $0.5 \mathrm{p} . \mathrm{u}$ then the MTG injected its power to Ac main grid around 0.5 p.u and another 0.5 p.u supplied the dc load of the microgrid. Furthermore, the same scenario can be seen in simulation time between 1620 seconds.

d. When de demand of dc microgrid exactly to MTG based power.

During this case and when the value of dc load is equal to the base power of MTG between times (9-12 seconds), the MTG will supply all its power to this load and the inverter just trying to stabilize the dc link voltage.

e. When none critical Dc load with based dc load.

When the non-critical dc load of microgrid switched on with based dc load and the MTG unable to provide it (more than 1 p.u) during the period from 12-16 second and from 2023 seconds, the bidirectional Ac/dc inverter working as rectifier and the power drawn from main Ac grid to dc link to compensate the required power of Dc microgrid, and the microturbine continue to generate 1 p.u as well as the extra power is come from Ac grid

The proposed design is very good to integrate the Ac main grid to de microgrid and very useful if this de microgrid has some renewable energy sources need to connect it to Ac grid.

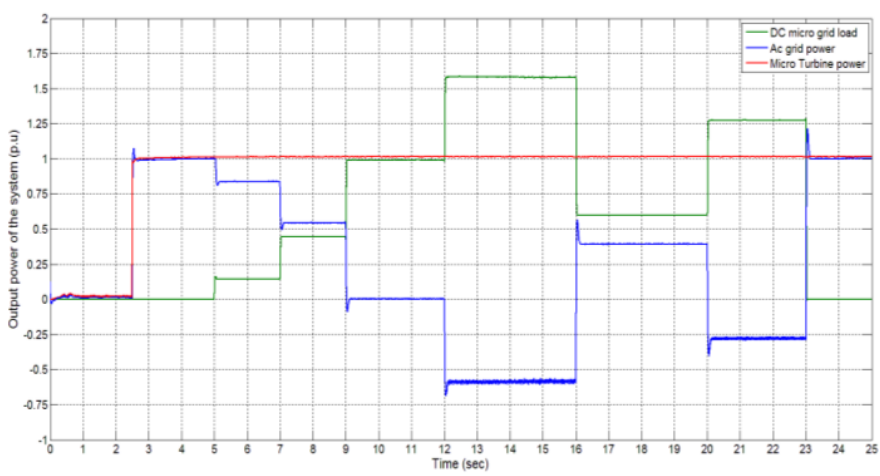

Fig. 10 Output power of the system in all scenario without GA-PI

Fig. 12 shown the microturbine speed 1 p.u and its reached to steady state after 2.5 seconds in case conventional methods, while its take 0.9 seconds in case of optimization methods. In additional, fig. 13 shown the output torque of MTG.

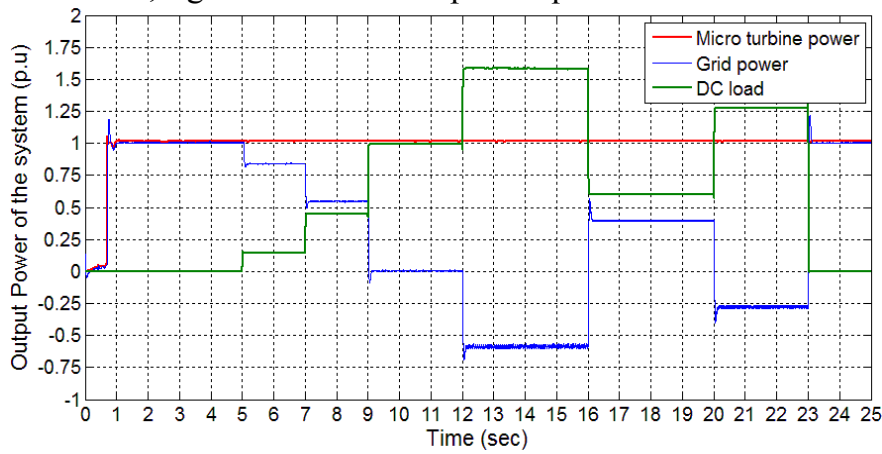

Fig.11 Output power of the system in all scenario with GA-PI

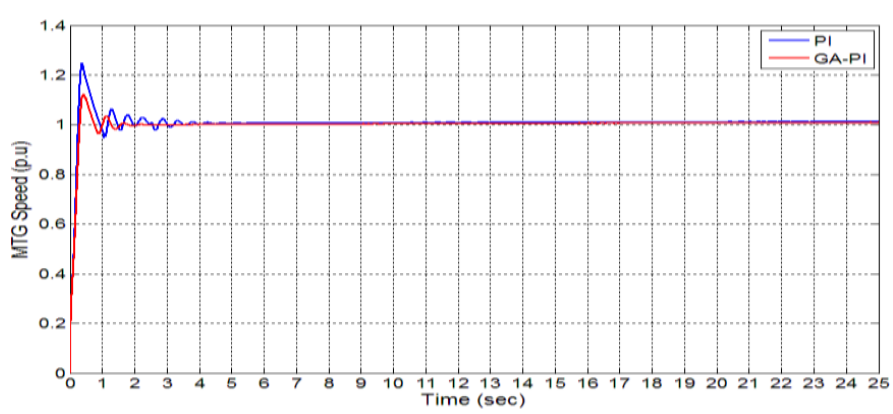

Fig.12 MTG speed in both cases

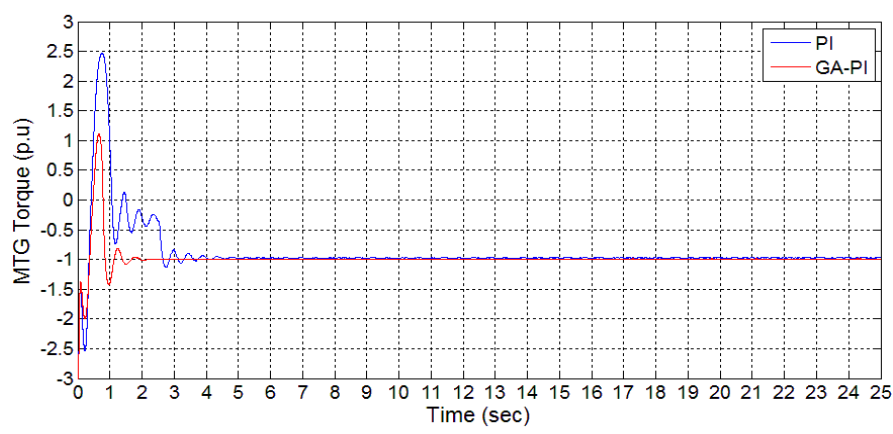

Fig.13 MTG output torque in both cases 


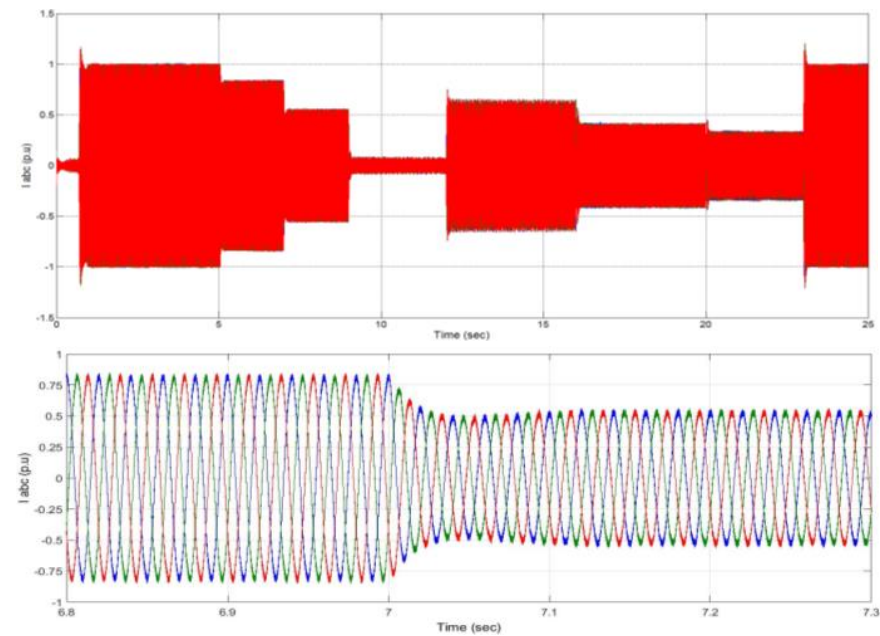

Fig.14 output I abc of inverter during changing the observe current from grid

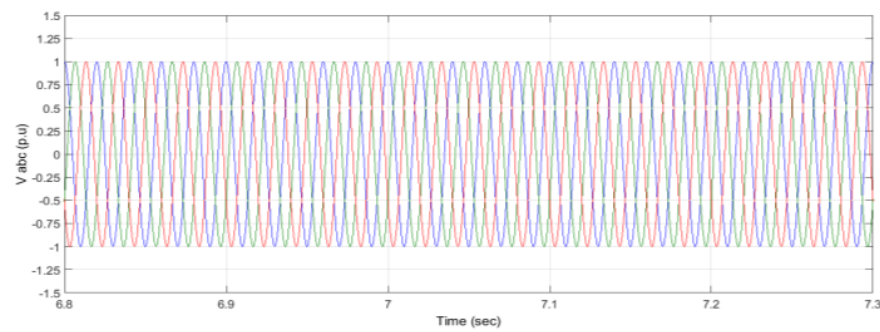

Fig. 15 output $\mathrm{V}$ abc of inverter

\section{Conclusion}

The proposal work investigated MTG modeling and finds an optimum parameter of MTG speed governor control. The high frequency rated the power of MTG converted to dc power; a bidirectional converter is designed to allow bidirectional power flow between dc link and Ac main grid to maintain dc link stable where dc link already connected to dc microgrid. The author made a comparison between conventional methods (trial and error) that tuning PI controller with proposed genetic algorithm. In addition, DC to DC buck converter based PI controller has been designed to regulate the suitable voltage of DC load.

\section{References}

[1] G. Ofualagba, "The Modeling and Simulation of a Microturbine Generation System," International Journal of Scientific \& Engineering Research, vol. 2, p. 7, 2012.

[2] D. Gaonkar, R. Patel, and G. Pillai, "Dynamic model of microturbine generation system for gridconnected/islanding operation," in Industrial Technology, 2006. ICIT 2006. IEEE International Conference on, 2006, pp. 305-310.

[3] G. Shankar and V. Mukherjee, "Load-following performance analysis of a microturbine for islanded and grid-connected operation," International Journal of Electrical Power \& Energy Systems, vol. 55, pp. 704-713, 2014.

[4] H. Cohen, G. F. C. Rogers, H. I. H. Saravanamuttoo, and H. Saravanamutto, "Gas turbine theory," 1987.
[5] L. Goldstein, B. Hedman, D. Knowles, S. I. Freedman, R. Woods, and T. Schweizer, "Gas-fired distributed energy resource technology characterizations," Golden, CO: National Renewable Energy Laboratory Report NREL/TP-620-34783, 2003.

[6] S. K. Nayak and D. Gaonkar, "Modeling and performance analysis of microturbine generation system in grid connected/islanding mode," in 2012 IEEE International Conference on Power Electronics, Drives and Energy Systems (PEDES), 2012, pp. 1-6.

[7] W. I. Rowen, "Simplified mathematical representations of heavy-duty gas turbines," Journal of engineering for power, vol. 105, pp. 865-869, 1983.

[8] A. Al-Hinai, K. Schoder, and A. Feliachi, "Control of grid-connected split-shaft microturbine distributed generator," in System Theory, 2003. Proceedings of the 35th Southeastern Symposium on, 2003, pp. 84-88.

[9] A. Saha, S. Chowdhury, S. Chowdhury, and P. Crossley, "Modeling and performance analysis of a microturbine as a distributed energy resource," IEEE Transactions on Energy Conversion, vol. 24, pp. 529-538, 2009.

[10] N. Sisworahardjo, M. El-Sharkh, and M. Alam, "Neural network controller for microturbine power plants," Electric Power Systems Research, vol. 78, pp. 1378-1384, 2008.

[11] F. Jurado and J. R. Saenz, "Adaptive control of a fuel cell-microturbine hybrid power plant," in Power Engineering Society Summer Meeting, 2002 IEEE, 2002, pp. 76-81.

[12] F. De Mello and D. Ahner, "Dynamic models for combined cycle plants in power system studies," IEEE Transactions on Power Systems (Institute of Electrical and Electronics Engineers);(United States), vol. 9, 1994.

[13] K. Bimal, "Bose," Modern power electronics and AC drives, 2002.

[14] O. Chee-Mun, "Dynamic simulation of electric machinery," ed: Prentice Hall, New Jersey, 1998.

[15] A. Mohamed, M. Elshaer, and O. Mohammed, "Bidirectional AC-DC/DC-AC converter for power sharing of hybrid AC/DC systems," in Power and Energy Society General Meeting, 2011 IEEE, 2011, pp. 1-8.

[16] M. P. Kazmierkowski and L. Malesani, "Current control techniques for three-phase voltage source PWM converters: A survey," IEEE Transactions on industrial electronics, vol. 45, pp. 691-703, 1998.

[17] V. Blasko and V. Kaura, "A new mathematical model and control of a three-phase AC-DC voltage source converter," IEEE transactions on Power Electronics, vol. 12, pp. 116-123, 1997.

[18] D. Hermawanto, "Genetic algorithm for solving simple mathematical equality problem," arXiv preprint arXiv:1308.4675, 2013.

[19] L. Davis, "Handbook of genetic algorithms," 1991.

[20] I. Griffin and J. Bruton, "On-line PID controller tuning using genetic algorithms," Dublin City University, 2003.

[21]T. Mahony, C. Downing, and K. Fatla, "Genetic algorithm for PID parameter optimization: minimizing error criteria," Process control and instrumentation, pp. 26-28, 2000. 